Qin $\mathrm{Xu}^{\star}$, Xing Wang and Shiping Wu

\title{
Hydraulic Study of Bubble Migration in Liquid Titanium Alloy Melt during Vertical Centrifugal Casting Process
}

https://doi.org/10.1515/htmp-2018-0002

Received January 04, 2018; accepted July 30, 2018

\begin{abstract}
The bubble migration in liquid titanium melt during vertical centrifugal casting process has been investigated by hydraulic experiments. Results show that the gas bubble in the simple cavity ultimately migrates like a line parallel to the wall in the opposite direction to the rotational casting mould. The deviation distance of the bubble in the simple geometry cavity tends to increase with the increment of the mould rotational speed during the migration process. And the gas bubble is much easier to migrate like a line when its initial position is nearer to the casting mould wall which is opposite to the mould rotational direction. The migration trajectories of bubbles located at different position in the complex cavity are more complicated than that in the simple cavity. The casting mould in the complex cavity can hamper both the radial movement and the circular movement of the bubble. And gas bubbles will gather, re-nucleate and form new bigger bubbles beside the casting mould wall. The re-formed gas bubbles in the complex cavity become bigger than which escape from bubble generation chamber.
\end{abstract}

Keywords: titanium alloy, vertical centrifugal casting, bubble migration, hydraulic simulation

Xu Qin, Female, Ph.D., lecture. Directions of research: theory and technology of materials solidification and structure control; numerical simulation of mould filling and solidification.

*Corresponding author: Qin Xu, School of Mechanic and Electrical Engineering, Henan University of Technology, Zhengzhou 450001, China, E-mail: xuqin_hit@163.com

Xing Wang, School of Mechanic and Electrical Engineering, Henan University of Technology, Zhengzhou 450001, China,

E-mail: wangxing@haut.edu.cn

Shiping Wu, School of Materials Science and Engineering, Harbin Institute of Technology, Harbin 150001, China,

E-mail: spwu@hit.edu.cn
Titanium alloys have been widely used in both military and commercial aircraft for its excellent properties, such as low density, high specific strength and good creepresisting property under high temperature [1-3]. However, the melting temperature of titanium alloys is high, and the viscosity of the melt is high, consequently the fluidity of the melt is poor [3]. Therefore, it is rather difficult to improve the filling property of the melt by increasing the pouring temperature. While the filling property can be improved by the centrifugal force developed by the high rotation speed during vertical centrifugal casting process for the filling time and the temperature decline degree can be reduced by the high centrifugal force, and hence improve the melt fluidity. Therefore, most of the titanium castings with big size and complex geometry structure are mainly produced by vertical centrifugal casting technology [4]. On the other aspect, titanium alloys show very high chemical activity at high temperature, and gases have high solubility in molten titanium alloys [5, 6]. The state of gases in the titanium alloy melts are mainly in the form of "solution" or "solid solution" state $[7,8]$. When the titanium alloys solidify, the gas solubility become smaller for the temperature drop of the liquid titanium alloy melts. Consequently, the gas solubilized in the melt escape from the liquid melt and bubbles eventually form in the alloys. Then some of the bubbles precipitate on the solid surface and form surface or subsurface porosity, while some of them are remained in the casting and form inner pores $[9,10]$.

Many researchers have observed the blowholes formed in the titanium alloys by x-ray radiography $[7,11]$, Neutron radiography inspection [8], numerical simulation analysis [12] and theoretical analysis [13], etc. Watanabe I. et al. [7] detected the casting porosity by x-ray radiography and calculated the porosity level by quantitative image analysis. Hero et al. [11] studied the porosity by x-ray radiography and density measurements. W.J. Richards et al. [8] inspected mold face coat inclusions in titanium investment castings by the neutron radiographic system of which the detection 
ability of the defects in the precision titanium alloy castings was highly improved. Chai et al. [12] studied the high Nb-TiAl alloy blade casts produced by investment casting process with numerical simulation method and results show that the shrinkage porosities in gravity casting are much more and dispersed than those in centrifugal casting. Sui et al. [13] studied the gas solubility, nucleation conditions, and nucleation rate, etc. in centrifugal casting liquid metal filling process by theoretical analysis.

The existence of gas holes and porosity in castings can greatly reduce their mechanical properties, air tightness, physical and chemical properties, and even can result in the rejection of casting. Measures must be taken to reduce or even prevent the gas defects in the titanium alloy castings. Watanabe's results show that smaller amount of porosity can be obtained by choosing an argon pressure difference and the smallest amount of porosity (approximately 0.8\%) will be getting in the specimens cast at 150 torr [7]. The experiments show that castings without a Ti foil contained little porosity, but the porosity can be averted by keeping smaller pressure differences between the melting furnace and the casting cavity [11]. A. Choudhury et al. found that by increasing the preheat temperature to $1,000^{\circ} \mathrm{C}$ can prevent the porosity in the TiAl alloy exhaust valve produced by the vertical centrifugal casting process [5]. Guttal S et al. [14] measured the influence of the sprue number and position on the porosity of cast titanium crowns. Results show that castings with double sprues have less internal porosity than those with single sprue. Fu P. X. and K.Liu et al. [15] studied the centrifugal casting process of TiAl exhaust valves and revealed that to moderately increase the gate size can effectively keep the feeding path open and there are no porosity in the casting with runner and gating systems in a staggered arrangement. WU MH et al. [16, 17] calculated the filling and solidification with different sprue designs (e.g., tree, ball, and runner-bar) by the MAGMASOFT software, and gas pore sensitivity were estimated based on the filling and solidification results. Results show that the sprue design is one of the most important factors in improving the property of casting titanium dentures.

As stated previously, the ultimate state of gas porosity, the effect on the casting properties, and how to reduce the gas porosity in titanium alloy castings have received considerable research attentions. However, very little work has been done on the bubble migration in liquid titanium alloy melt which will affect the formation of the gas porosity. Thus, the aim of the present work is to study the bubble migration in the liquid Ti-6Al-4V alloy melt in the simple and complex cavities during vertical centrifugal casting process.

\section{Experimental procedure}

The rotational velocity range of centrifugal casting machine used in the model experiment is $0 \sim 1200 \mathrm{rpm}$, so different rotational velocities can be selected in the experiment and its effect on the bubble migration will be investigated. The high-speed camera used in the study can take 1,000 pictures per second, and can meet the need of the experiment. The schematic diagram of hydraulic simulation apparatus is shown in Figure 1 and the polymethyl methacrylate (PMMA) casting mold for hydraulic simulation of bubble migration is shown in Figure 2. The bubble generation chambers were made on the bottom of the casting mould according to the positions shown in Figure 2(a), (b), (c), (d) and (e). The geometry structure of the bubble generation chamber is shown in Figure 2(f).

In order to study the effect of the geometry structure on the bubble migration in titanium alloy melt during vertical centrifugal casting process, the bubble migration in two different casting mould cavities were studied in the experiment. The cavities are the casting molds with simple geometry structure as a "rectangle" and the casting molds with complex geometry structure as a half of Chinese characters "Happiness". The schematic of the casting molds with simple geometry structure and complex geometry structure are shown in Figure 3(a) and Figure 3(b), respectively. Different mould rotational velocities (shown in Table 1) were used in the experiment, and the casting mould rotates clockwise in the experiment.

The simulated medium in the experiment is mainly water. From the reference [18] and the data provided by ProCAST software, we know that the viscosity of water at $6-7^{\circ} \mathrm{C}$ is equal to that of the TC4 alloy melt at the liquidus temperature, that is about $1.45 \times 10^{-3} \mathrm{~Pa}$.S. And the viscosity of water at $11-12^{\circ} \mathrm{C}$ is equal to that of the TC4 alloy melt with superheat temperature of $100^{\circ} \mathrm{C}$, that is about $1.257 \times 10^{-3} \mathrm{~Pa}$.S. The room temperature when we did the hydraulic experiment is about $20^{\circ} \mathrm{C}$, and the viscosity of water at $1.01325 \times 10^{5} \mathrm{~Pa}, 20^{\circ} \mathrm{C}$ is $1.01 \times 10^{-3} \mathrm{~Pa}$.S. Therefore, the tackifier is added into the simulated water for the viscosity of water is smaller than the real liquid melt, and consequently to make the viscosity of the simulated 


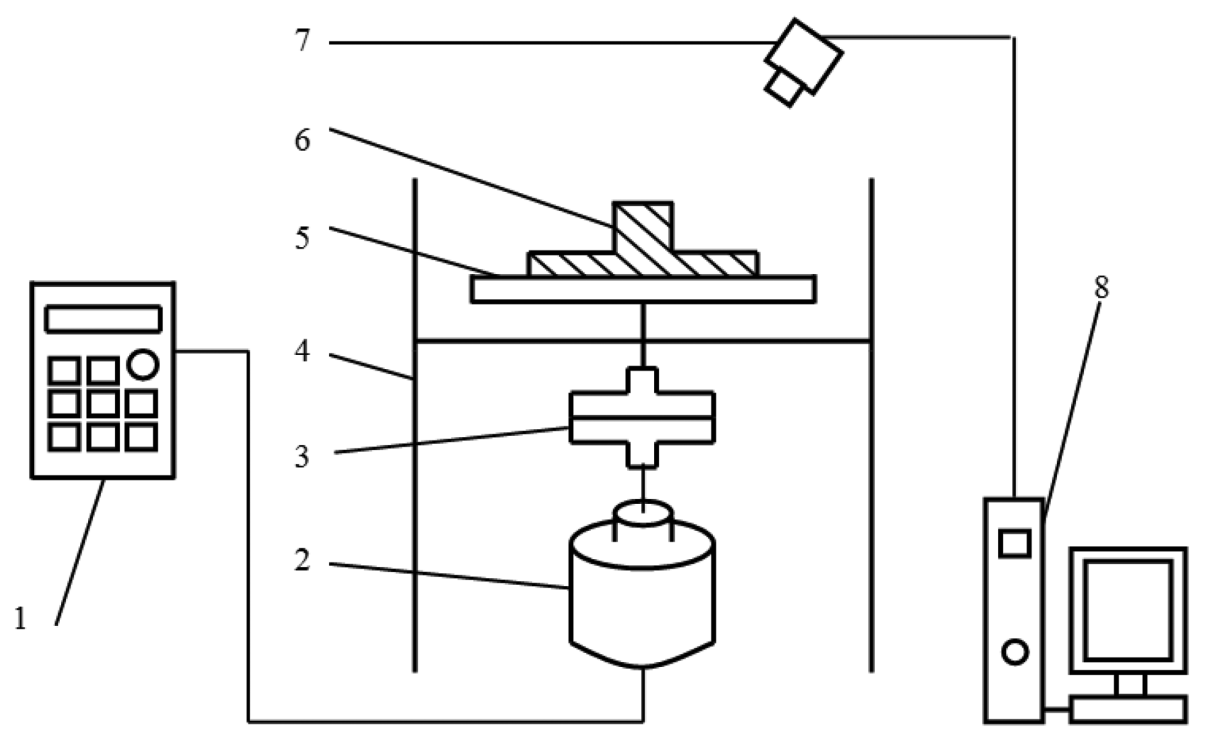

Figure 1: Schematic diagram of hydraulic simulation apparatus for bubble migration in titanium melt during vertical centrifugal casting process. 1-HT6000 frequency converter; 2-Three-phase AC Motor; 3-Hydraulic coupling; 4-Protective covering; 5-Centrifugal plate; 6-Casting mould; 7-High-speed camera; 8-Data processing system

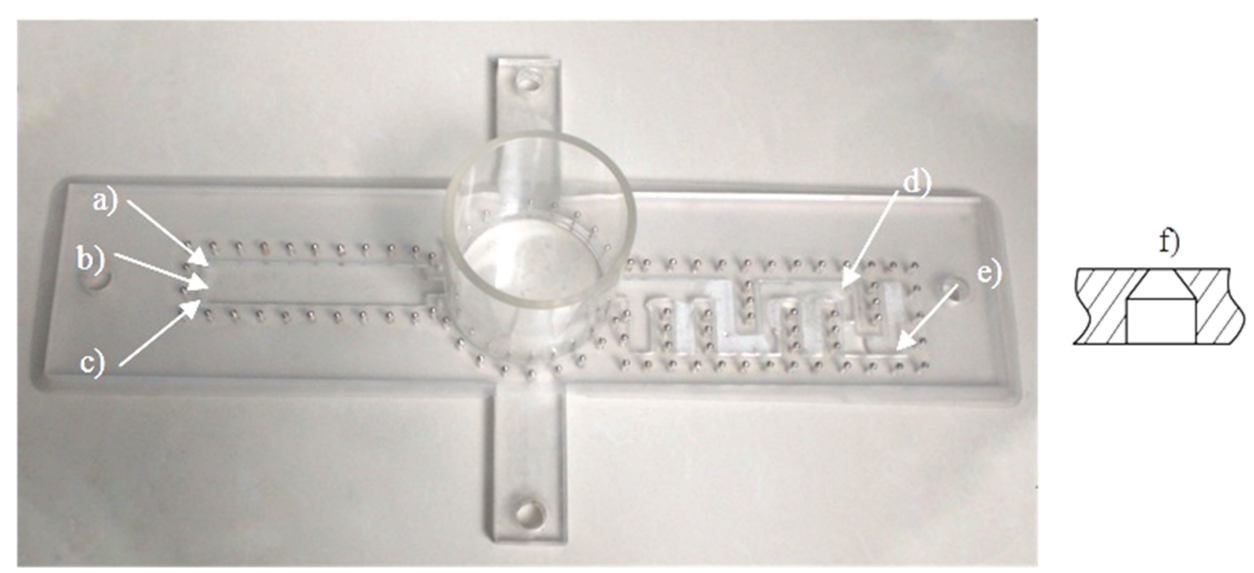

Figure 2: PMMA casting mold for physical simulation of bubble migration.

medium identical to that of the titanium alloy. Thus, they can meet the physical simulation similarity criterion of the titanium alloy during its mold filling in the vertical centrifugal casting process. In order to make the captured images more clearly, white background is set on the bottom of the mould and a certain amount of red dye is added into the simulated medium.

Before the experiment has been carried out, the bubble chamber is preset on the PMMA casting mold. Then a small piece of $\mathrm{CaC}_{2}$ particle is put into the dried bubble chamber and the chamber is tightly sealed. After that, the PMMA casting mold will be fixed on the centrifugal turn- table. When the centrifugal turntable is rotating at a certain stable rotating speed, the simulated medium will be poured into the rotating casting mold. At the meantime, the high speed camera is started and the bubble moving process will be shot until the moving trajectory is steady.

\section{Experimental results and discussions}

To the best of our knowledge, titanium alloys are usually melted and poured in the vacuum induction furnace at $\mathrm{Ar}$ 

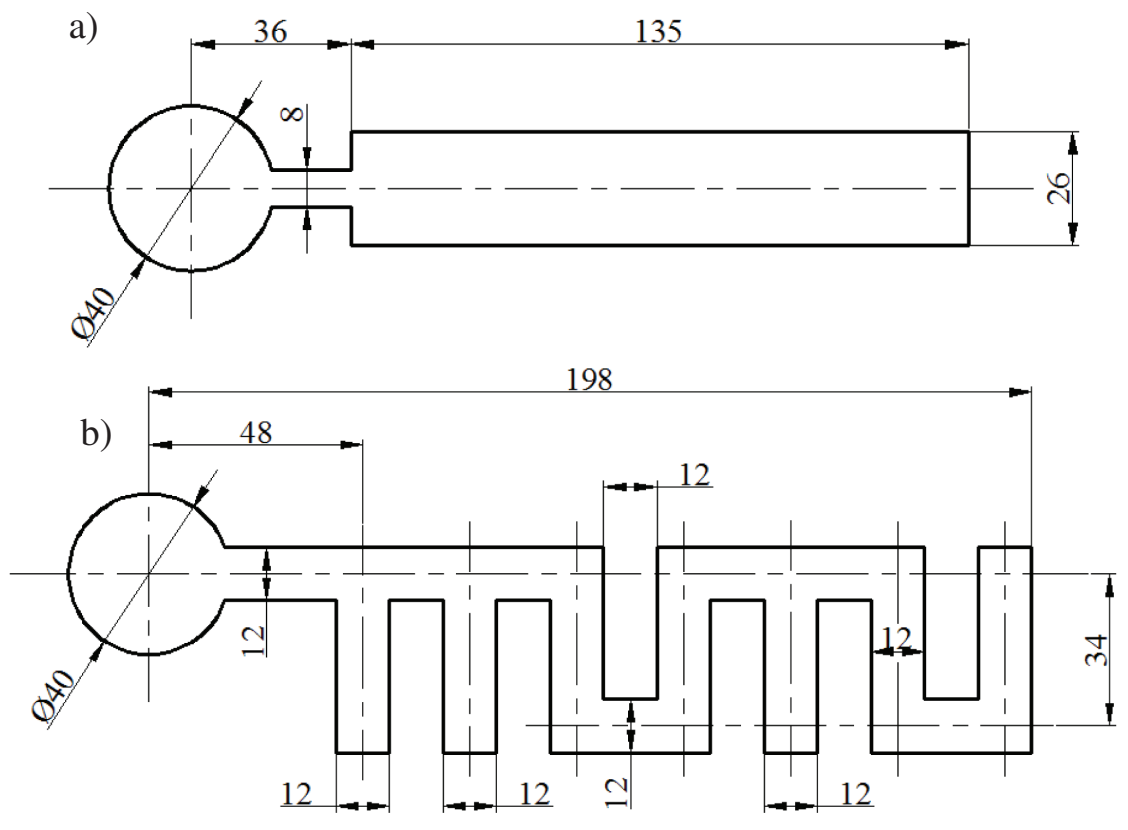

Figure 3: The PMMA casting molds and their dimensions.

a) simple geometry cavity; b) complex geometry cavity

Table 1: Selection of mould rotation speed.

\begin{tabular}{lrr}
\hline Experiment NO. & Motor frequency/HZ & Rotational velocity/rpm \\
\hline 1 & 5.15 & 160 \\
2 & 10.13 & 300 \\
3 & 13.46 & 400 \\
4 & 16.8 & 500 \\
\hline
\end{tabular}

atmosphere. So gas porosities in titanium alloy castings cannot form in the filling process by air entrapment. However, the liquid titanium alloy melt will first expose to the outer wall of the mould during the filling process and it shows very high chemical activity with the casting mould wall at high temperature. And gas porosities always form at the outer surface of casting by the reaction of the liquid melt and the casting mould after the melt fill the cavity. Therefore, we will study the bubble migration of the reactive gas pores in the titanium castings during vertical centrifugal casting process in the present paper.

\section{Bubble migration trajectory in the simple cavity}

Figure 4 shows the migration trajectory of bubble at position a), b) and c) in the simple cavity shown in
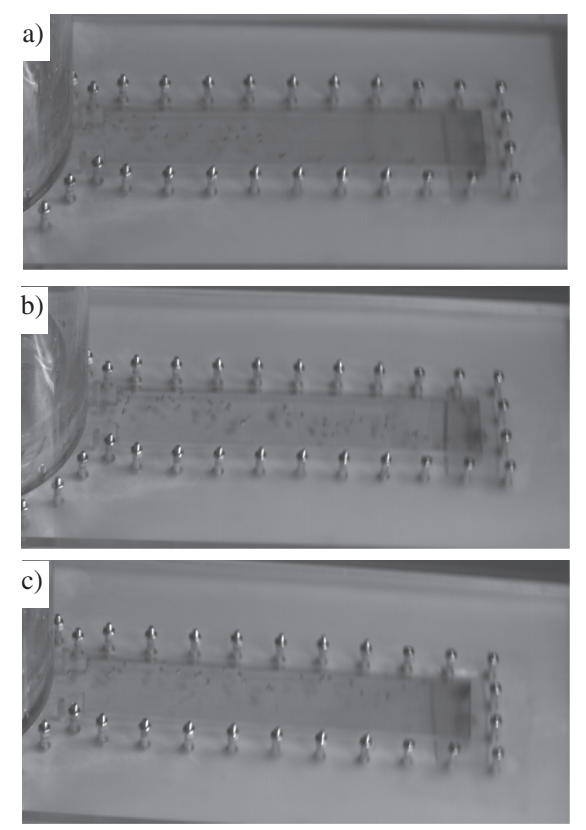

Figure 4: Migration trajectory of bubble at different position in simple cavity (clockwise, $300 \mathrm{rpm}$ ).

a) position of Figure 2(a); b) position of Figure 2(b); c) position of Figure 2(c)

Figure 2 when the casting mould rotated clockwise at speed of $300 \mathrm{rpm}$. From Figure 4(a) and (b) we can see that the migration of bubble located at position a) and b) 
in Figure 2 during vertical centrifugal casting process can be divided into the radial movement forward to the casting rotating shaft and the circular movement opposite to the direction of the rotating mould. After a period of time, the bubbles continue to migrate like a line parallel to the casting mould wall in the direction opposite to the rotational casting mould. From Figure 4(c) we can see that the gas bubble migrates to the rotating shaft like a line close to the casting mould wall in the opposite direction to the rotational casting mould when the bubble posited at position c).

As is shown in Figure 2, the bubble at position a) in the simple cavity is posited at the location close to the mold wall near the rotation direction of the rotating mould, while the bubble at position b) is posited at the location at the center line of the two casting mould wall. And the bubble at position c) is posited at the location near the mold wall opposite to the rotation direction of the casting mould. For the casting mold wall has a blocking effect on the circular movement, therefore, the migration trajectory of the bubble at position a) in Figure 2 is a line close to the casting mould wall in the opposite direction to the rotation of the mould and the ultimate migration trajectory of the bubble at position b) and c) in Figure 2 is like a line close to the casting mould wall in the opposite direction of the casting mould.

\section{Bubble migration trajectory in the complex cavity}

Figure 5 shows the migration trajectory of bubble at position d) and e) in the complex cavity shown in
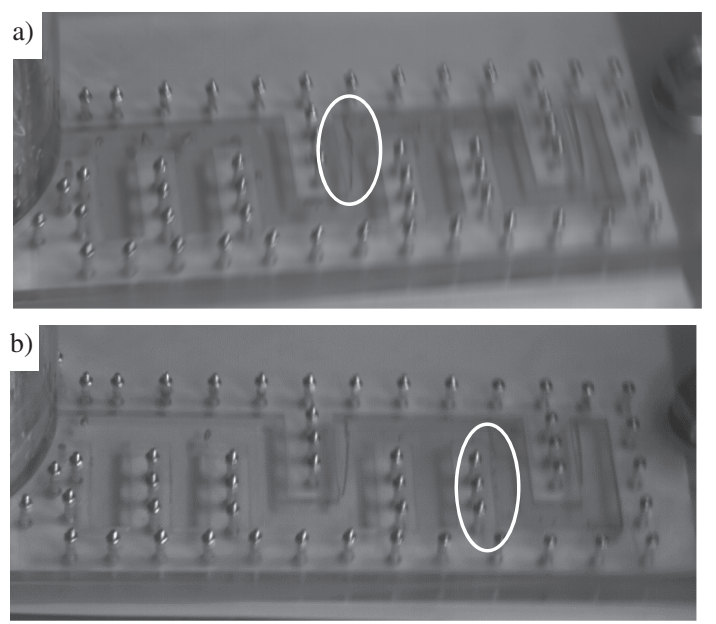

Figure 5: Migration trajectory of bubble at different position in complex cavity (clockwise, $300 \mathrm{rpm}$ ).

a) position shown in Figure $2(d)$; b) position shown in Figure 2(e)
Figure 2 when the mould rotated clockwise at speed of $300 \mathrm{rpm}$. Compared with the bubble migration trajectories in the simple cavity, the migration trajectories of bubbles at different position in complex cavity become more complicated. The gas bubbles in the simulated liquid at position d) first migrate along the casting mould wall in the direction opposite to the rotation of the mould, and then they gather at the white ellipse zone shown in Figure 5(a) for the blocking effect of the complex geometry shape of the casting mould on the bubble migration. After the gases reaching a certain amount, they re-nucleate and form new bigger bubbles along the casting mould wall and continue to move toward the rotating shaft of the casting mould. On the other aspect, we can see that the re-formed gas bubbles in the complex cavity become much bigger than which escape from bubble generation chamber.

While the migration of gas bubbles at position e) can be divided into the radial movement forward to the casting rotating shaft and the circular movement opposite to the direction of the rotating mould during their initial moving stage. Then the gas bubbles will change their migration direction and begin to move along the casting mould wall which located at the opposite direction of the rotational casting mould for the blocking effect of the mould wall at the white ellipse zone shown in Figure 5 (b). When the bubbles migrate to the end of this mould wall, the blocking effect disappears, and the bubbles will continue to move to the casting rotating shaft again. The bubble migration thereafter is similar to the bubble migration at position d). However, the moving speed of the bubble is much lower.

Through the above analysis we can know that the migration process of bubbles located at position e) is more complicated than that of bubbles form at position d). We can also find a very interesting phenomenon, the mould wall at the white ellipse zone shown in Figure 5(a) and Figure 5(b) all have blocking effect on the bubble migration, however, the gas bubbles gather at the ellipse zone in Figure 5(a) while not gather in Figure 5(b). This can be attributed to the different blocking effect of the mould wall on the bubble migration. The mould wall at the ellipse zone in Figure 5(a) hampered both the radial movement and the circular movement, while the mould wall at the ellipse zone in Figure 5(b) only hampered the radial movement of the gas bubble. And the bubble at the ellipse zone in Figure 5(b) can also move circumferentially to the wall in the opposite direction of the rotating mould. Therefore, the gas bubbles cannot gather at the ellipse zone in Figure 5(b). 
To summarize, the bubble migration is influenced not only by complexity of the casting mould cavity and the number of the barriers in the mould cavity, but also by the different blocking effect of the casting mould wall on the bubble migration.

\section{Effect of mould rotational speed on the bubble migration trajectory}

Figure 6 shows the migration trajectory of bubble at position b) in the simple cavity shown in Figure 2 under
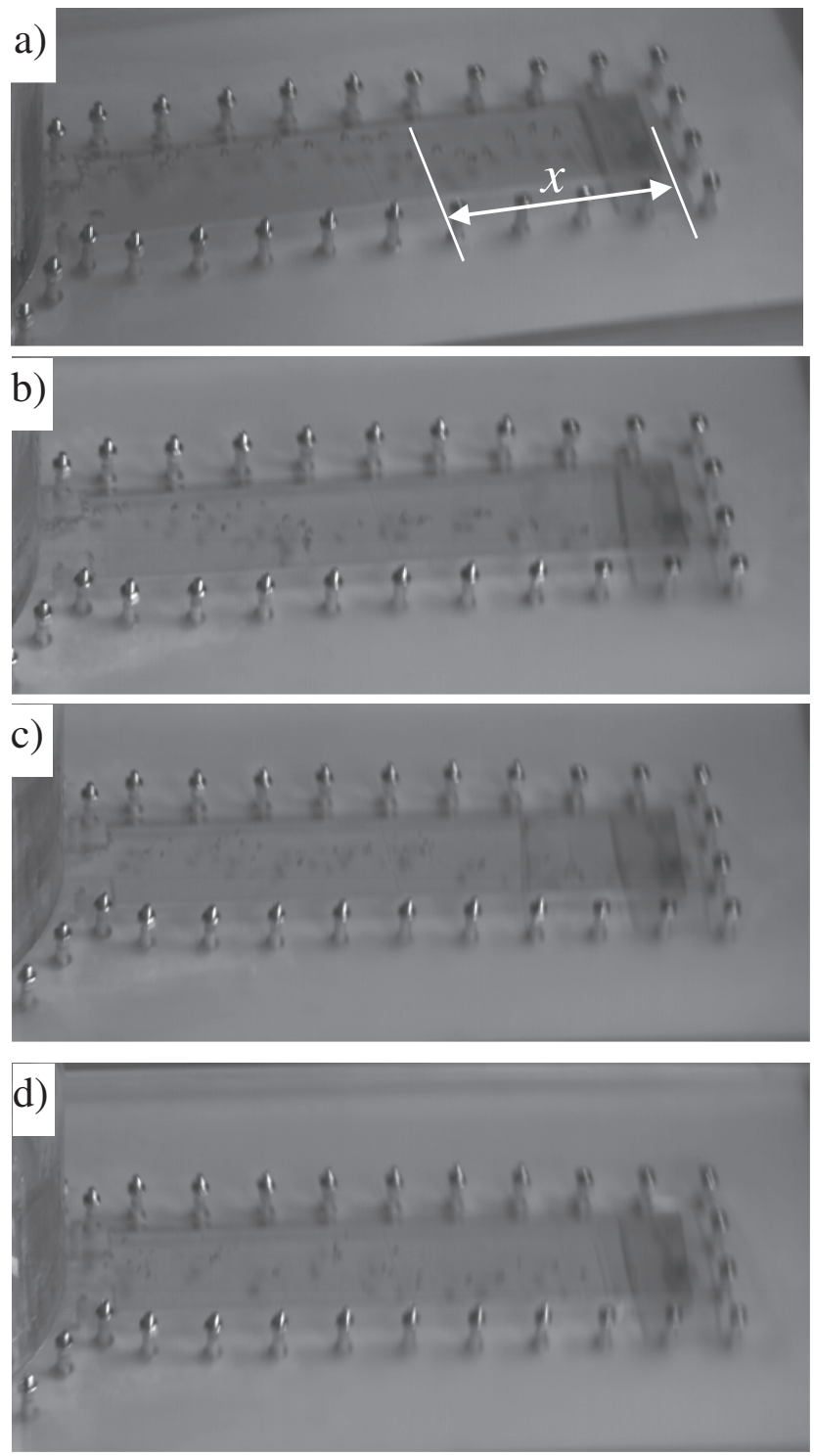

Figure 6: Migration trajectory of bubble with different mould rotational speed (clockwise).

a) $160 \mathrm{rpm}$; b) $300 \mathrm{rpm}$; c) $400 \mathrm{rpm}$; d) $500 \mathrm{rpm}$ different mould rotational speed when the mould rotates clockwise. The results show that whether the rotational speed is high or low, the bubble migration trajectory in the titanium alloy melts under vertical centrifugal casting process can all be divided into the radial movement forward to the casting rotating shaft and the circular movement opposite to the direction of the rotating mould. And the casting mould wall has an impeditive effect on the circular movement during the bubble moving process. Therefore, the gas bubble ultimately migrates to the casting rotating shaft like a line close to the casting mould wall in the opposite direction of the rotation casting mould. On the other aspect, the distance from the position where the bubble starts to migrate like a line to its initial position in the simple cavity is different when the rotational speed of the casting mould is different. In this paper, the distance from the position where the bubble begin to migrate like a line to the bubble initial position (that is the position of the bubble generation chamber) will be described as "Deviation distance" and it will be discussed in detail in section "The deviation distance of bubble in the simple cavity".

Figure 7(a) and (b) show the migration trajectories of bubble at position d) in the complex cavity shown in Figure 2 when the mould rotates clockwise at $300 \mathrm{rpm}$ and $400 \mathrm{rpm}$ respectively. As has been described in section "Bubble migration trajectory in the complex cavity", the gas bubbles re-nucleate and form new bigger bubbles
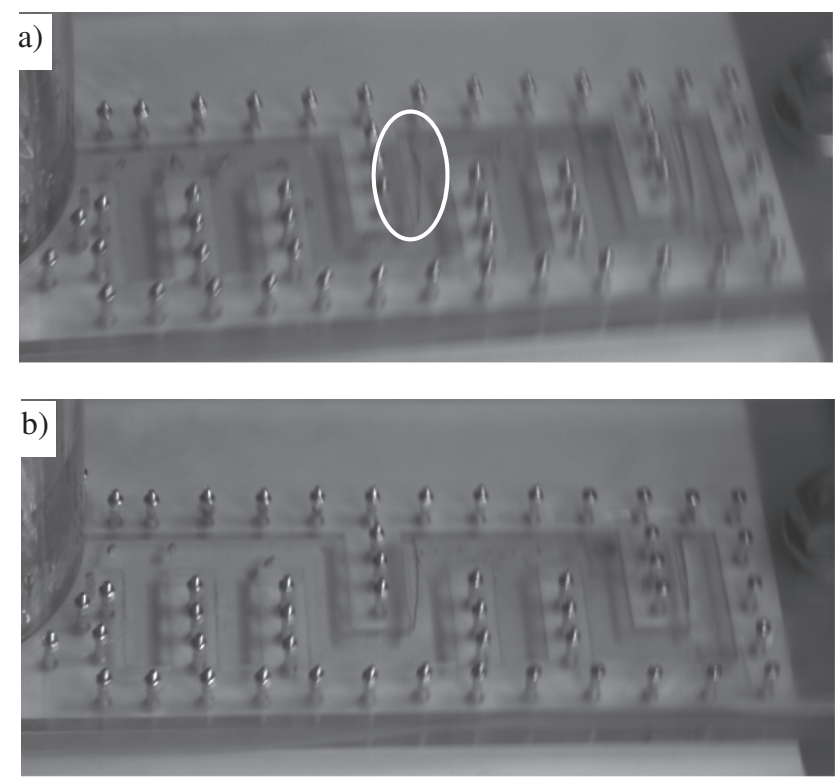

Figure 7: Migration trajectory of bubble at different position in complex cavity (clockwise).

a) $300 \mathrm{rpm}$, position shown in Figure 2(d); b) $400 \mathrm{rpm}$, position shown in Figure 2(d) 
along the casting mould wall in the white ellipse zone. The number of the re-formed bubbles becomes less and the volume of the re-formed bubbles becomes much bigger than that when the bubbles escape from bubble generation chamber. Furthermore, from Figure 7 we can also see that the number of the re-formed bubbles become less and the volume of the re-formed gas bubbles become smaller with the increment of the casting mould rotational speed. This can be attributed to the pressure difference at different position under different casting rotational speed.

\section{The deviation distance of bubble in the simple cavity}

As has been stated before, because of the blocking effect of the casting mould wall on the bubble migration, the bubbles in the simple cavity tend to migrate like a line parallel to the casting mould wall in the direction opposite to the rotational casting mould. In this paper, the distance from the bubble initial position to the position where the bubbles begin to migrate like a line is described as "Deviation distance", and is denoted by " $\mathrm{x}$ " in Figure 6(a).

Figure 8 show the deviation distance of bubble in the simulated liquid under different rotational speed at position b) in the simple cavity shown in Figure 2 when the mould rotates clockwise. From Figure 8 we can see that the deviation distance of bubble increase with the increment of the casting rotational speed. When the casting mould rotates at $150 \mathrm{rpm}$, the bubble deviation distance is about $55 \mathrm{~mm}$, while the bubble deviation distance increase to $95.5 \mathrm{~mm}$ when the casting mould rotates at $300 \mathrm{rpm}$. Consequently, the gas bubbles in the titanium alloy melt are easily to form surface or subsurface blowholes near the casting mould wall when the casting mould rotational speed is lower. Thus, the increment of the casting rotational speed can make bubble more easily migrate from the cavity to the gating system. And it can therefore reduce the gas porosity in the titanium alloy melt during its vertical centrifugal casting process by increasing the mould rotational speed. The relationship between the deviation distance " $\chi$ " and the casting mould rotational speed $\omega$ can be expressed approximately exponentially as follows,

$$
x=-185^{\star} \exp (-\omega / 433)+184
$$

Figure 9 show the deviation distance of bubble at different bubble initial position in the simple cavity shown in Figure 2 when the mould rotates clockwise at $300 \mathrm{rpm}$. From Figure 9 we can see that when the initial position of the gas bubble located at position a), the deviation distance of bubble is about $112 \mathrm{~mm}$. And when the initial position of the gas bubble located at position c), the deviation distance of bubble sharply decrease to about $2 \mathrm{~mm}$. That is, when the initial position of the bubble located at the position which is more close to the casting mould wall opposite to the mould rotational direction, the deviation distance of bubble is much smaller. Consequently, the gas bubble is much easier to migrate like a line while the initial position of the bubble is nearer to the casting mould wall opposite to the mould rotational direction. And the bubbles are easier to remove from the liquid melt. Therefore, it is much difficult to form gas pores in the castings in the practical casting process.

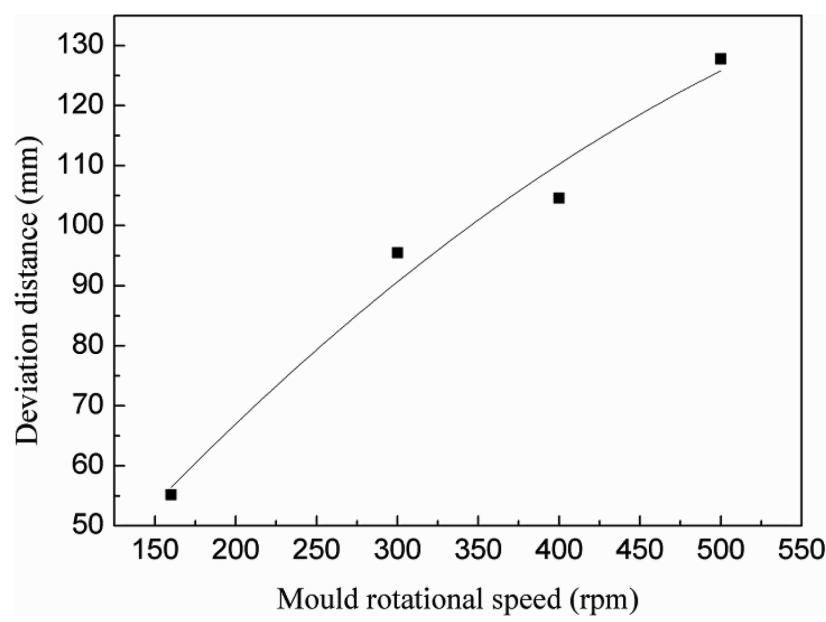

Figure 8: Deviation distance of bubble under different rotational speed (position in Figure 2(b)).

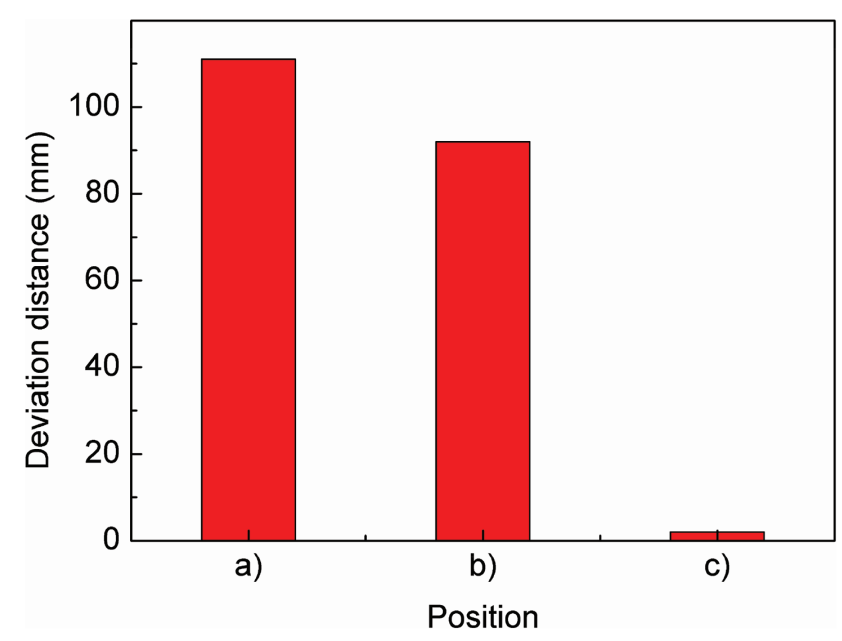

Figure 9: Deviation distance of bubble at different position (300 rpm). 


\section{Conclusions}

(1) The bubble migration in the simple cavity during vertical centrifugal casting process can be divided into the radial movement forward to the casting rotating shaft and the circular movement opposite to the direction of the rotating mould.

(2) The casting mould in the complex cavity can hamper both the radial movement and the circular movement of the bubble. And gas bubbles will gather, re-nucleate and form new bigger bubbles beside the casting mould wall when the wall hampered both the radial movement and the circular movement, while the bubbles only change the migration direction when the wall only hampered the radial movement.

(3) The deviation distance of the bubble in the simple geometry cavity tends to increase with the increment of the mould rotational speed during the migration process. When the initial position of the bubble lies near the wall opposite to the mould rotational direction, the bubble is prone to move in a linear way.

Funding: This work was supported by Foundation items: The Initial Scientific Research Fund of Young Teachers in Henan University of Technology (Grant No. 2018QNJH25) and the National Natural Science Foundation of China (Grant No.51605144).

\section{References}

[1] J.C. Williams and E.A. Starke, Jr., Acta. Mater. , 51 (2003) 5775-5799.
[2] Y. Yang, R. Chen, Q. Wang, et al., Int. Commun. Heat. Mass. Transfer. , 90 (2018) 56-66.

[3] S. Wu, Q. Xu, J. Zhang, H. Nan, X. Xue and J. Guo, Chin Foundry, 08 (2011) 218-222.

[4] J.X. Zhou, X. Shen, Y.J. Yin, et al., Gas-liquid Two Phase Flow Modelling of Incompressible Fluid and Experimental Validation Studies in Vertical Centrifugal Casting, (2015).

[5] Y. Sui, K. Feng, C. Cheng, et al., J. Wuhan Univ. Technol. (Materials Science), 31 (2016) 1105-1108.

[6] S. Xiao, Y. Chen, H. Zhu, J. Tian and B. Wu, Raremetal Mater. Eng., 35 (2006) 678-681. (in Chinese).

[7] I. Watanabe, J.H. Watkins, H. Nakajima, M. Atsuta and T. Okabe, J. Dent. Res., 76 (1997) 773-779.

[8] W.J. Richards, J.R. Barrett, M.E. Springgate and K.C. Shields, Appl. Radiat. Isot. , 61 (2004) 675-682.

[9] H. Nan, C. Liu, D. Huang, J. Zhao and H. Zhao, Chin. Foundry, 5 (2008) 12-15.

[10] Y. Ling, J. Zhou, H. Nan, et al, J. Mater. Process. Technol. ,251 (2018) 295-304.

[11] H. Hero, M. Syverud and M. Waarli, J. Mater. Sci-Mater Med., 4 (1993) 296-299.

[12] L. Yang, L. Chai, Y. Liang, Y. Zhang, C. Bao, S. Liu and J. Lin, Intermetallics, 66 (2015) 149-155.

[13] Y. Sui, B. Li, A. Liu, Y. Xiong, J. Guo and H. Fu, Chin. J. Mater. Res., 22 (2008) 580-584. (in Chinese).

[14] S.S. Guttal and N.P. Patil, Quintessence Int., 38 (2007) 78-82.

[15] P. Fu, X. Kang, Y. Ma, K. Liu, D. Li and Y. Li, Intermetallics, 16 (2008) 130-138.

[16] M. Wu, P.R. Sahm, M. Augthun, H. Spiekermann and J. Schädlich-Stubenrauch, J. Mater. Sci-Mater. Med., 10 (1999) 519-525.

[17] M. Wu, I. Wagner, P.R. Sahm and M. Augthun, J. Mater. Sci. Mater. Med., 13 (2002) 301-306.

[18] H.J. Kretzschmar and W. Wagner, Properties of Water and Steam, Springer-Verlag,Berlin (2008). 